\title{
Comparison of hemocyte parameters in the pericardial cavity and the adductor muscle sinus in the Pacific oyster, Crassostrea gigas using two types of flow cytometers
}

\author{
Béatrice Gagnaire ${ }^{1,2}$, Matthieu Duchemin ${ }^{3,4}$, Michel Auffret ${ }^{3}$, Hélène Thomas-Guyon ${ }^{1}$ and Tristan \\ Renault $^{2, a}$ \\ ' Centre de Recherche sur les Ecosystèmes Littoraux Anthropisés, UMR 6217, avenue Michel Crépeau, 17042 La Rochelle, France \\ 2 IfREMER La Tremblade, Laboratoire de Génétique et Pathologie, 17390 La Tremblade, France \\ 3 Laboratoire des Sciences de l'Environnement Marin, UMR CNRS 6539, Institut Universitaire Européen de la Mer, \\ Université de Bretagne Occidentale, place Nicolas Copernic, 29280 Plouzané, France \\ 4 Institut Armand-Frappier, Institut National de la Recherche Scientifique, Campus de Pointe-Claire, 245 Hymus, Pointe-Claire, \\ H9R 1G6, Québec, Canada
}

Received 4 October 2007; Accepted 4 December 2007

\begin{abstract}
Parameters of hemocyte populations have been considered as relevant indicators of bivalve health and are currently used in immunotoxicological studies. Hemocytes in hemolymph can be collected by puncturing either the pericardial cavity or the adductor muscle sinus with a syringe. Flow cytometry is a methodological approach that is increasingly being used in laboratories for the study of hemocyte parameters in aquatic invertebrates. However, various protocols for hemocyte processing in laboratories equipped with different types of cytometers have been published. In this context, two flow cytometers (EPICS XL4®, Beckman Coulter and FacsCalibur $囚$, Becton Dickinson) and two sites of hemocyte collection (pericardial cavity and adductor muscle sinus) were compared for the analysis of hemocyte parameters in the Pacific oyster, Crassostrea gigas. Hemolymph cells were analyzed in terms of their number and organelle contents. Cell mortality, phagocytosis, non specific esterase, extension of the lysosomal compartment and production of reactive oxygen species were quantified. The results showed that the phagocytic index was higher for hemocytes obtained in the muscle sinus hemolymph. The results are discussed with respect to the potential use of flow cytometry as a tool for hemocyte studies in bivalves.
\end{abstract}

Key words: Flow cytometry / Hemocytes / Phagocytosis / Crassostrea gigas

\section{Introduction}

Bivalve molluscs have an open circulatory system consisting of a circulating compartment which lacks capillaries. A complex network of sinuses is localised in various organs, the most important ones being located within the pericardial cavity and the adductor muscle (Cheng 1981). As a consequence, hemocytes may either circulate in vessels, but may also be resting in interstitial tissues of organs. Studies have been done in bivalve hemocytes collected either from the pericardial fluid (Cheng and Downs 1988; Sauvé et al. 2002) or from the adductor muscle sinus hemolymph (Auffret et al. 2002; Chu et al. 2002; Lambert et al. 2007). These cells play a key role

\footnotetext{
a Corresponding author: trenault@ifremer.fr
}

in non-specific defence mechanisms and many of the hemocyte parameters are used for immunotoxicological diagnosis (Auffret 2005). Hemocytes are involved in the recognition of invading pathogens and in their elimination by phagocytosis and encapsulation (Cheng 1981; Fisher 1986). Hydrolytic enzymes including esterases and the release of reactive oxygen species (ROS) play key roles in pathogen degradation (Pipe 1992). Moreover, lysosomes have been described as a valid marker of cell viability (Moore et al. 1978). Assessing either the functions of these cells or any possible disruptions induced by environmental stressors requires efficient and reliable methodologies in the domain of cell biology. Furthermore, comparisons of results obtained by different laboratories would be possible if standardized procedures were adopted. 
Flow cytometry is increasingly being used to analyse the structure and function of bivalve hemocytes (Ford et al. 1994; Fournier et al. 2002; Gagnaire et al. 2006). In this context, a comparative study was conducted using the Pacific oyster, Crassostrea gigas, a common biological model in marine bivalve studies. Two laboratories, one equipped with a FacsCalibur@ (Becton Dickinson), the other with an EPICS XL4® (Beckman Coulter) flow cytometer, but both using the same software, participated in this study. The questions to be addressed focused on: i) the hemocyte parameters relative to the site for hemolymph collection (pericardial fluid or muscle hemolymph) and ii) the type of cytometer used for cell analyses. Several hemocyte parameters including cell viability, oxygen-dependant antimicrobial activity, non specific esterase, extension of the lysosomal compartment and phagocytic index were measured according to well established flow cytometry protocols. Total hemocyte count (THC), volume of hemolymph and total number of cells were also monitored using conventional methods.

\section{Material and methods}

\subsection{Animals and assay schedule}

Adult Pacific oysters, C. gigas, with a shell length of 2$3 \mathrm{~cm}$, were reared for 16 months in external raceways at the IFREMER's hatchery in La Tremblade (Charente-Maritime, France) from February 2002 to June 2003.

The analyses were performed on a same batch of oysters during two periods: in June 2003 at LEMAR Laboratory (Brest University) using a FacsCalibur $($ Becton Dickinson) and then three weeks later at IFREMER (La Tremblade) using an EPICS XL4® (Beckman Coulter). The two flow cytometers were both equipped with a $488 \mathrm{~nm}$ argon-ion laser. Data were processed using WinMDI 2.8 software (Windows version). When animals had to be transferred, they were kept in seawater at ambient temperature for one night and then processed the day after the transfer.

\subsection{Hemolymph collection}

Hemolymph was withdrawn using a syringe equipped with a needle $(0.9 \times 25 \mathrm{~mm})$ either from the pericardial cavity after carefully opening the shell, or from the sinus of the adductor muscle after breaching the shell with pincers (Auffret and Oubella 1995; Lambert et al. 2007). 0.5-1.5 ml of hemolymph was collected from each oyster. The hemolymph was stored on ice until processed to reduce spontaneous aggregation. Three pools of ten animals each were used for both collection sites. For each pool, the volume of hemolymph was recorded and hemocytes were counted using a Malassez counting chamber to determine the hemocyte concentration (number of cells per $\mathrm{ml}$ ). From these data, the total number of collected cells was calculated for each pool.

\subsection{Flow cytometer analyses}

Three thousand events were counted per sample for each cytometer. Data were collected at a specific photomultiplier tube (PMT) fluorescence, at 500-550 nm for cell mortality (red fluorescence) and 560-670 nm for other parameters (green fluorescence). A FSC threshold was defined in order to eliminate cell debris and bacteria. Hemocyte parameters were assessed using protocols previously described (Gagnaire et al. 2006). Each measurement required $200 \mu \mathrm{l}$ of hemocyte suspension.

Previously described protocols for bivalve immunology were applied. In brief, hemocytes were incubated in the dark for $30 \mathrm{~min}$ at $4{ }^{\circ} \mathrm{C}$ with $10 \mu \mathrm{l}$ of propidium iodide (PI, $1.0 \mathrm{mg} \mathrm{L}^{-1}$, Interchim) to quantify cell mortality.

A phagocytic index was measured ex vivo as the proportion of cells that had ingested three or more fluorescent beads. Hemocytes were incubated for one hour in the dark at ambient temperature with $10 \mu \mathrm{l}$ of a $1 / 10$ dilution of Fluorospheres ${ }^{\circledR}$ carboxylate-modified microspheres $(1 \mu \mathrm{m}$ diameter, Interchim). The final ratio of beads:hemocytes was 135:1. The hemocyte phagocytic capacity (HPC) was calculated as the mean number of engulfed beads within the phagocytic haemocytes population (Lehmann et al. 2000).

The production of cellular Reactive Oxygen Species (ROS) was measured using dihydrorhodamine 123 (DHR123, Molecular Probes), specific for superoxide anion $\mathrm{O}_{2}^{-}$. Non-specific esterase activity was measured using the substrate fluoresceine diacetate (FDA, Molecular Probes).

The extension of the lysosomal compartment was measured using a commercial kit (LysoTracker ${ }^{\circledR}$ Green DND-26, $500 \mu \mathrm{M}$ in DMSO, Molecular Probes). For these three parameters, one $\mu$ l of a DHR123 solution $(145 \mu \mathrm{M})$, a FDA solution $(400 \mu \mathrm{M})$ or a LysoTracker aliquot was added to hemocytes, respectively. Cells were then incubated for $30 \mathrm{~min}$ for esterase activity and ROS production and two hours for lysosome presence. Incubations took place in the dark at room temperature and the reaction was stopped on ice $(5 \mathrm{~min})$.

The samples were prepared in each of the labs during two trials and subsequently analyzed in the cytometer available there. For cell analysis, gates were defined on the cytograms in order to distinguish different populations according to fluorescence intensity as previously described (Gagnaire et al. 2006).

\subsection{Statistical analyses}

Data were arcsine square root transformed to achieve normality. For hemocyte concentration, volume and total hemocyte count, means were compared by performing the Student $t$-test. For flow cytometry results, statistical analysis was done only on the population of highly stained cells (Gagnaire et al. 2006). Student $t$ tests were carried out on collection sites for each cytometer using Statgraphics ${ }^{\circledR}$ Plus version 5.1 software.

\section{Results and discussion}

The total volume of fluid withdrawn from the adductor sinus was three times larger than that from the pericardial cavity, $p<0.001$ (Fig. 1). Microscopical examination of samples showed that muscle hemolymph was less cluttered with particles such as gametes and bacteria than pericardial fluid. Hemocyte concentration and total cell counts were not significantly different between collection sites (Fig. 1). 


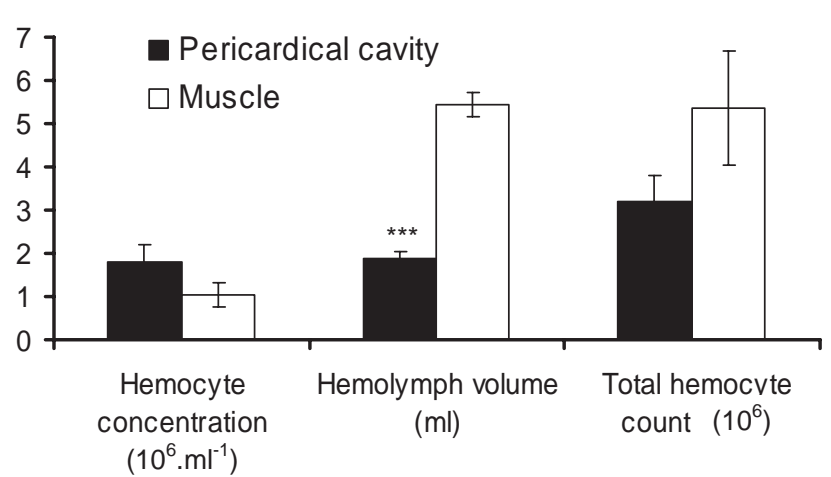

Fig. 1. Hemocyte concentration, hemolymph volume and total hemocyte count for pericardial fluid and muscle hemolymph. $N=6$ replicates; standard error is shown, $* * *: p<0.001$.

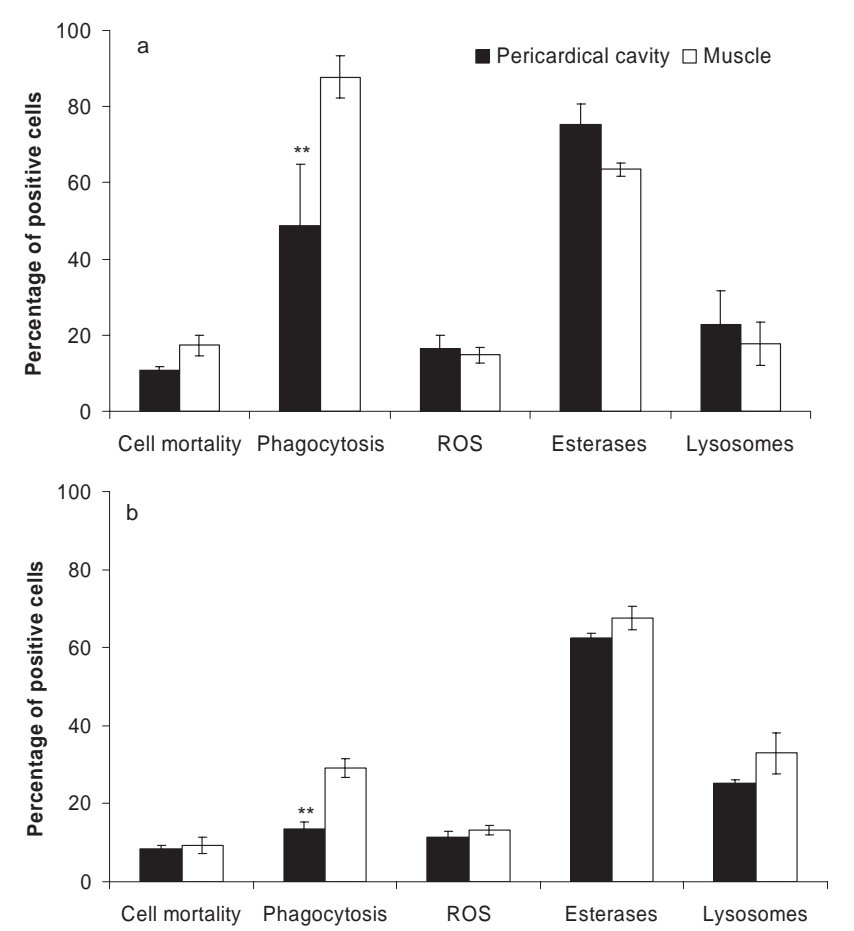

Fig. 2. Hemocyte activities monitored by two flow cytometers, Beckman Coulter EPICS XL 4® (a) and Becton Dickinson FacsCalibur $\mathbb{R}$ (b), in pericardial fluid and muscle hemolymph: hemocyte mortality, phagocytic index, percentage of ROS positive cells, percentage of esterase positive cells and percentage of lysosome positive cells. $N=3$ replicates; standard error is shown, * represents a significant difference between pericardial cavity and muscle hemocytes, $* *: p<0.01$.

No significant differences for cell mortality, ROS, esterase and lysosome percentages of positive cells were found between the pericardial fluid and the muscle hemolymph when analysed with the EPICS XL4® and the FacsCalibur ( (Figs. 2a,b). However, values for cell mortality tended to be higher using the EPICS XL $4 \AA$ compared to the FacsCalibur $($.

For both cytometers, the phagocytic index was higher for hemocytes collected from the muscle sinus compared to the pericardial cavity ( $p<0.01$, Figs. $2 \mathrm{a}, \mathrm{b}$ ). However, there was no difference in hemocyte phagocytic capacity (assessed only with the FacsCalibur $($ ) of hemocytes collected from the two sites (data not shown).

When both trials were compared, both the cell morality and the phagocytic index tended to be higher using the EPICS XL $4 囚$. However, the phagocytic index ratio of the two sites of hemocyte collection remained comparable at 1:2 (pericardial fluid: muscle hemolymph).

Using the Pacific oyster as a model, the first aim of these experiments was to compare the two sites of hemolymph collection based upon the evaluation of their hemocyte parameters. Hemolymph collected from the sinus of the adductor muscle yielded a larger volume of fluid with less undesirable particles (gametes and bacteria) than that extracted from the pericardial cavity.

This study reveals that the origin of hemocytes may interfere with assays for hemocyte functions. Indeed, the phagocytic index of the pooled hemocyte population collected in the muscle hemolymph was twice as high as that obtained from the pericardial fluid. Furthermore, we showed that this discrepancy could not be explained by a difference in the average number of beads engulfed (hemocyte phagocytic capacity, HPC), that is, the capacity of hemocytes collected from the two sites to perform phagocytosis. This clearly demonstrates that uneven index values might result from a lower number in phagocytic cells rather than from a reduction of their activity as immune cells. Another hypothesis is that the difference observed among collection sites may be due to two different patterns of hemocyte sub-populations.

The exact origin of bivalve hemocytes remains unknown, but different sub-populations of hemocytes, mainly granulocytes and hyalinocytes, exist through different patterns (see review by Cheng 1981; Hine 1999). Granulocytes showed higher phagocytic activities than hyalinocytes in Crassostrea virginica (Goedken and De Guise 2004) and in Mytilus edulis (Pipe et al. 1997) whereas chemicals, such as copper, induced changes in these hemocyte patterns after a few days of in vivo exposures (Pipe et al. 1999). However, even though flow cytometry can be used to differentiate hemocyte sub-populations (Gagnaire et al. 2006), no such data was generated in this study. Experiments should be continued in order to obtain this type of data.

It is important to note that the pericardial cavity and the anterior adductor muscle sinus have different physiological roles. While the anterior adductor muscle sinus is involved in the hemolymph circulation throughout the body, the heart and particularly the auricles have been described as a major site of bioaccumulation and detoxication of xenobiotics in bivalves (trace metals; polycyclic aromatic hydrocarbons (PAHs), polychlorobiphenyls (PCBs) and of ultrafiltration (Zaroogian and Yevich 1994). Moreover, both collection sites (adductor muscle sinus and pericardial cavity) have very little physical connection between them and do not exert the same functions in bivalve physiology (Cheng 1981). Finally, specific hemocytes called serous cells or brown hemocytes reside in the pericardial cavity and are devoted mostly to excretion (Hine 1999). Exposure to chemicals may have different immunotoxic effects on various immune cells. In mice for example, permethrin, an insecticide, induced different effects on immune cells collected 
from blood compared to those collected from nephros (Prater et al. 2002). Mercury also induces different immunotoxic effects in macrophages than in neutrophils (Cunha et al. 2004). Consequently, in any further studies assessing these immune endpoints or other hemocyte parameters, one should carefully consider which site the hemocytes are to be collected, at least in the case of the Pacific oyster, Crassostrea gigas. This study also raises the question of the differential role of hemocytes in the immune functions.

In terms of differences between cytometers used to analyse hemocytes from the same site of withdrawal, both the phagocytic index and cell mortality tended to be higher using the EPICS XL 4®. This may be due to the delay (three weeks) be-

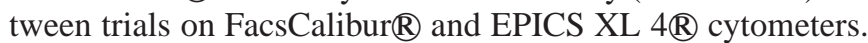
A seasonal survey of Pacific oysters (Duchemin et al. 2007) has shown that the phagocytic index of hemocytes collected from the muscle sinus can vary by $8 \%$ to $30 \%$ depending on the time of the year. Another explanation could be variations in electronic specifications and signal treatment by the FSC pho-

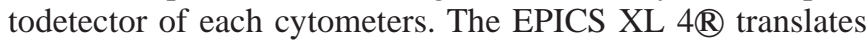
bead sizes in increasing order (from left to right, increasing size from $3 \mu \mathrm{m}$ to $8 \mu \mathrm{m})$. The FacsCalibur $囚$ inverts bead sizes (from left to right, sizes are $4 \mu \mathrm{m}, 3 \mu \mathrm{m}, 6 \mu \mathrm{m}, 5 \mu \mathrm{m}, 8 \mu \mathrm{m}$ and $7 \mu \mathrm{m})$ (Becker et al. 2001).

The measurement of phagocytosis using flow cytometry remains the most relevant parameter to assess the status of the immune system in bivalve hemocytes. Since the assay is always performed ex vivo (Lehmann et al. 2000), other comparisons could be performed relative to the size of the beads and the bead-to-cell ratio following the ingestion of $2 \mu \mathrm{m}$ (Auffret et al. 2002), $1.7 \mu \mathrm{m}$ (Sauvé et al. 2002) or $1 \mu \mathrm{m}$ (Fournier et al. 2002) fluorescent beads or labelled bacteria (Allam et al. 2001).

No difference in ROS, esterase and lysosome percentage of positive cells were noted between cytometers or between collection sites. This result demonstrates the robustness of the protocols which have been developed. These activities have, however, been shown to be modulated in vitro in contaminated hemocytes compared to controls (Gagnaire et al. 2006). These results further show the potential value of measuring such parameters for immunotoxicological studies.

\section{Conclusion}

This study touches upon some elements to consider when conducting standardised immunotoxicological studies in bivalves and reveals that hemocyte assessment may differ depending on the site of collection. These differences could be the basis for further studies on hemocytes. Finally, these preliminary results have highlighted the need for the harmonization and standardization of bivalve immune endpoints assessment methods.

From a technical perspective, puncture of hemolymph in the pericardial cavity takes less time to be performed than for the sinus of the adductor muscle and could be recommended when processing a high number of oysters while puncture into the muscle should be used when large volumes of hemolymph are needed.
Acknowledgements. The authors gratefully thank B. Walker for improving the English of this manuscript. This work was partly supported by the Poitou-Charentes and Brittany regions.

\section{References}

Allam B., Ashton-Alcox K.A., Ford S.E., 2001, Haemocyte parameters associated with resistance to brown ring disease in Ruditapes spp. clams. Dev. Comp. Immunol. 25, 365-375.

Auffret M., 2005, Bivalves as models for marine immunotoxicology, In: Tryphonas H., Fournier M., Blakley B.R., Smits J.E.G., Brousseau P. (Eds.) Investigative Immunotoxicology, Models And Approaches In Immunotoxicology. CRC Press, pp. 29-48.

Auffret M., Mujdzic N., Corporeau C., Moraga D., 2002, Xenobioticinduced immunomodulation in the European flat oyster, Ostrea edulis. Mar. Environ. Res. 54, 585-589.

Auffret M., Oubella R., 1995, Cytological and cytometric analysis of bivalve mollusc hemocytes, In: Stolen J.S., Fletcher T.C., Smith S.A., Zelikoff J.T., Kaattari S.L., Anderson R.S., Söderhäll I., Weeks-Perkins B.A. (Eds.) Techniques in Fish Immunology Immunology and Pathology of Aquatic Invertebrates, Fair Haven, NJ, USA, SOS Publications, pp. 55-64.

Becker C., Parker J., Hechinger M., 2001, Is forward scatter monotonic on commercial flow cytometers?, International Society for Analysis, its Applications and Computation Conference, Berlin, Germany.

Cheng T.C., 1981, Bivalves, In: Ratcliffe N.A., Rowley A.F. (Eds.) Invertebrate Blood Cells I, London, Academic Press, pp. 233299.

Cheng T.C., Downs J.C., 1988, Intracellular acid phosphatase and lysozyme levels in subpopulations of oyster, Crassostrea virginica, hemocytes. J. Invertebr. Pathol. 52, 163-167.

Chu F.L., Volety A.K., Hale R.C., Huang Y., 2002, Cellular responses and disease expression in oysters (Crassostrea virginica) exposed to suspended field contaminated sediments. Mar. Environ. Res. $53,17-35$.

Cunha E.M., Oliveira M.J., Ferreira P.G., Aguas A.P., 2004, Mercury intake by inflammatory phagocytes: in vivo cytology of mouse macrophages and neutrophils by X-ray elemental microanalysis coupled with scanning electron microscopy. Hum. Exp. Toxicol. 23, 447-53.

Duchemin M., Fournier M., Auffret M., 2007, Seasonal variations of immune parameters in diploid and triploid Pacific oysters, Crassostrea gigas (Thunberg). Aquaculture 264, 73-81.

Fisher S.W., 1986, Structure and functions of oyster hemocytes, In: Brehélin M. (Eds.) Immunity in Invertebrates, Berlin Heidelberg, Springer-Vrelag, pp. 25-35.

Ford S.E., Ashton-Alcox K.A., Kanaley S.A., 1994, Comparative cytometric and miroscopic analyses of oyster hemocytes. J. Invertebr. Pathol. 64, 114-122.

Fournier M., Pellerin J., Lebeuf M., Brousseau P., Morin Y., Cyr D., 2002, Effects of exposure of Mya arenaria and Mactromeris polynyma to contaminated marine sediments on phagocytic activity of hemocytes. Aquat. Toxicol. 59, 83-92.

Gagnaire B., Thomas-Guyon H., Burgeot T., Renault T., 2006, Pollutant effects on Pacific oyster, Crassostrea gigas (Thunberg), hemocytes: screening of 23 molecules using flow cytometry. Cell Biol. Toxicol. 22, 1-14. 
Goedken M., De Guise S., 2004, Flow cytometry as a tool to quantify oyster defence mechanisms. Fish Shellfish Immunol. 16, 539552.

Hine P.M., 1999, The inter-relationships of bivalve haemocytes. Fish Shellfish Immunol. 9, 367-385.

Lambert C., Soudant P., Degremont L., Delaporte M., Moal J., Boudry P., Jean F., Huvet A., Samain J-F., 2007, Hemocyte characteristics in families of oysters, Crassostrea gigas, selected for differential survival during summer and reared in three sites. Aquaculture 270, 276-288.

Lehmann A.K., Sornes S., Halstensen A., 2000, Phagocytosis: measurement by flow cytometry. J. Immunol. Meth. 243, 229-242.

Moore M.N., Lowe D.M., Fieth P.E.M., 1978, Lysosomal responses to experimentally injected anthracene in the digestive cells of Mytilus edulis. Mar. Biol. 48, 297-302.

Pipe R.K., 1992, Generation of reactive oxygen metabolites by the haemocytes of the mussel Mytilus edulis. Dev. Comp. Immunol. $16,111-122$.
Pipe R.K., Farley S.R., Coles J.A., 1997, The separation and characterisation of haemocytes from the mussel Mytilus edulis. Cell Tissue Res. 289, 537-45.

Pipe R.K., Coles J.A., Carissan F.M.M., Ramanathan K., 1999, Copper induced immunomodulation in the marine mussel, Mytilus edulis. Aquat. Toxicol. 46, 43-54.

Prater M.R., Gogal Jr R.M., Blaylock B.L., Longstreth J., Holladay S.D., 2002, Single-dose topical exposure to the pyrethroid insecticide, permethrin in C57BL/6N mice: effects on thymus and spleen. Food Chem. Toxicol. 40, 1863-1873.

Sauvé S., Brousseau P., Pellerin J., Morin Y., Senecal L., Goudreau P., Fournier M., 2002, Phagocytic activity of marine and freshwater bivalves: in vitro exposure of hemocytes to metals ( $\mathrm{Ag}, \mathrm{Cd}, \mathrm{Hg}$ and $\mathrm{Zn}$ ). Aquat. Toxicol. 58, 189-200.

Zaroogian G., Yevich P., 1994, The nature and function of the brown cell in Crassostrea virginica. Mar. Environ. Res. 37, 355-373. 